\title{
ASSOCIAÇÃO ENTRE RESPOSTAS INDIVIDUAIS DA COMPOSIÇÃO CORPORAL E PRESSÃO ARTERIAL SITÓLICA APÓS TREINAMENTO AERÓBIO EM IDOSAS HIPERTENSAS
}

\author{
Wagner dos Santos Júnior (IC); Marina Lívia Venturini Ferreira; Alex Castro; Cláudia Regina Cavaglieri; Mara \\ Patrícia Traina Chacon Mikahil.
}

\section{Resumo}

O presente estudo teve como objetivo verificar a associação entre mudanças na composição corporal (massa magra e massa gorda) e a Pressão Arterial (PA) na posição supina, após 12 semanas de treinamento aeróbio contínuo. Participaram do estudo 32 voluntárias (randomizadas em grupo treino aeróbio - TA $(n=26$, idade $=57,23 \pm 6,91$ anos; peso $=81,66 \pm 17,91 \mathrm{~kg} ; \mathrm{IMC}=31,23 \pm 5,91)$ e grupo controle, sem treinamento $-\mathrm{GC}(\mathrm{n}=6$, idade $=61,07 \pm 4,95$ anos; peso $=81,82 \pm 16,22 \mathrm{~kg} ; \mathrm{IMC}=31,41 \pm 5,72$ ). Para análise da PA, foi utilizado a fotopletismografia de dedo, através do equipamento Finometer, e a composição corporal, foi avaliada por pletismografia por deslocamento de ar, utilizando o equipamento Bod Pod. As comparações inter e intra momentos foram realizadas utilizando Modelo Linear Misto; a associação entre a mudança na composição corporal e PA foram realizadas por Regressão Linear Simples. As respostas individuais da PA, não foram relacionadas com as respostas individuais da composição corporal.

\section{Palavras-chave: Hipertensão arterial, Composição Corporal, Treinamento Aeróbio.}

\section{Introdução}

A Hipertensão Arterial é um estado fisiológico onde a pressão arterial se encontra acima dos limites considerados normais (Pressão Arterial Sistólica - PAS> que $140 \mathrm{mmHg}$ e Pressão Arterial Diastólica - PAD> 90 $\mathrm{mmHg}$ ). A pressão arterial elevada de forma crônica, pode acarretar outras doenças cardiovasculares. No Brasil, $25,7 \%$ da população é hipertensa (MINISTÉRIO DA SAÚDE, Vigitel, 2016), sendo que após a menopausa, a mulher se torna mais suscetível a doenças cardiovasculares, devido à redução dos níveis de hormônios femininos (principalmente o estrogênio) (MCARDLE et al., 2016). Elevados valores de gordura corporal, estão associados com quadros de obesidade, aumentando marcadores inflamatórios, contribuindo para o quadro de hipertensão.

\section{Resultados e Discussão}

Através das análises por Modelo Linear Misto, pudemos verificar que não existiu associação entre as alterações nos componentes da composição corporal e a alteração da pressão arterial, em resposta ao estimulo de treino a que o grupo foi submetido. Para determinação de responsividade, foi adotado o duas vezes o valor do Erro típico da medida (ETM), que para pressão arterial foi de $10 \mathrm{mmHg}$ de PAS e $-5 \mathrm{mmHg}$ para PAD; $-2 \mathrm{~kg}$ para massa gorda; e $+2 \mathrm{~kg}$ para massa magra.

Foram encontradas diferenças entre as respostas individuais, em relação às alterações da gordura corporal e respostas da pressão arterial (Figura 1), embora sendo encontradas voluntárias que responderam de maneira significativa na redução da gordura corporal $(>2 \mathrm{~kg})$ e/ou na redução da PAS (> $10 \mathrm{mmHg}$ ). Após análise de Regressão Linear Mista, essas variáveis parecem não ter associação nos momentos pré e pós $\left(r^{2}=0,1504 ; P=\right.$ $0,421)$. Comparando os dados da alteração da massa magra e a resposta da pressão arterial (Figura 2), encontramos uma situação semelhante a da massa gorda, onde não foram encontradas associações nos momentos pré e pós $\left(r^{2}=0,0776 ; P=0,198\right)$.
Figura 1. Relação entre a diferença na massa gorda vs variação da pressão arterial sistólica nos momentos pré e pós programa de treinamento aeróbio contínuo.

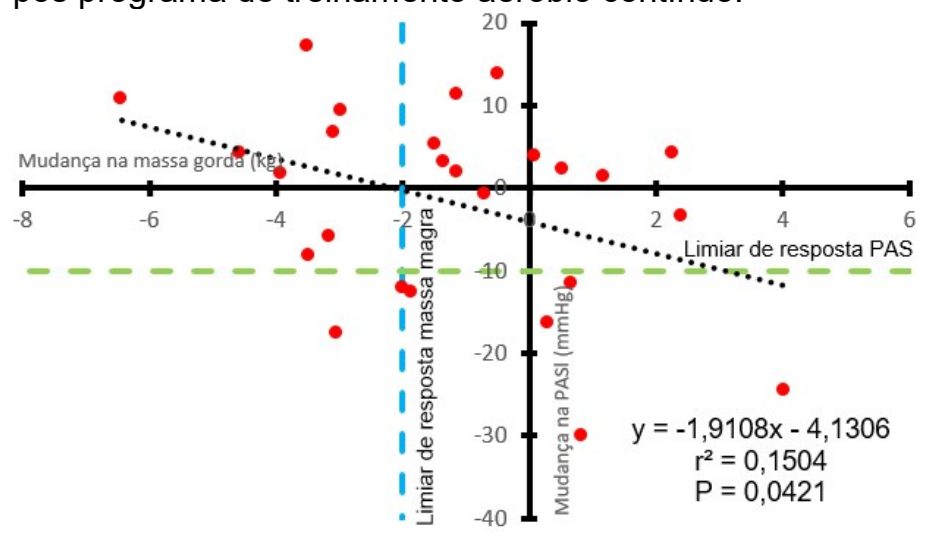

Figura 2. Relação entre a diferença na massa magra vs variação da pressão arterial sistólica nos momentos pré e pós pós programa de treinamento aeróbio contínuo.

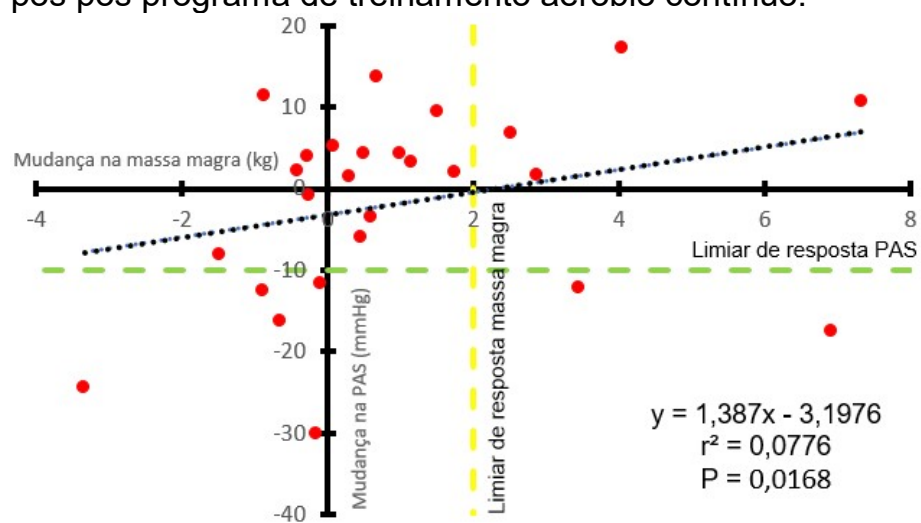

\section{Conclusões}

As variações nas respostas individuais da pressão arterial sistólica não estão associadas as variações individuais das mudanças da composição corporal em hipertensas idosas.

Agradecimentos

CNPq, CAPES, FAEPEX, SAE, FISEX - FEF Unicamp. 